\title{
Inhaled vasodilator therapy in acute lung injury: first, do NO harm?
}

The acute respiratory distress syndrome in adults (ARDS) is defined by refractory hypoxaemia in the presence of radiographic evidence of bilateral pulmonary infiltrates. ${ }^{1}$ The full-blown syndrome and lesser degrees of acute lung injury (ALI) are characterised by the presence of high permeability alveolar oedema, a loss of hypoxic pulmonary vasoconstriction (HPV) leading to a marked increase in ventilation-perfusion mismatch, and increased pulmonary vascular resistance (PVR). Adverse changes in ventilationperfusion account almost wholly for the hypoxaemia that characterises ALI/ARDS ${ }^{2}$ and the rise in PVR is commonly associated with clinically significant right ventricular dysfunction ${ }^{3}$ leading, in turn, to preload limitation, septal shift, and impaired left ventricular performance. ${ }^{45}$ The detrimental effects on cardiac performance almost certainly contribute to morbidity and, in some patients, mortality.

The capacity of conventional vasodilator therapy to influence these events remains limited and this approach is plagued with difficulties. Firstly, non-specific vasodilation has a global pulmonary effect, abolishing any remaining hypoxic pressor response and causing a further deterioration in ventilation-perfusion. Secondly, doses required to produce a beneficial effect on the pulmonary vasculature frequently induce systemic vasodilation and cardiovascular instability. Nevertheless, several such agents have been employed and none have emerged as universally efficacious. Nitrate vasodilators, ${ }^{6}$ calcium channel blockers, ${ }^{7}$ and the vasodilator eicosanoids ${ }^{89}$ have all been used in ALI/ARDS, the latter provoking interest because of associated beneficial effects, such as improved cardiac performance, tissue perfusion, and platelet disaggregation. In this context, the issues are complex in that oxygen delivery to respiring tissues may be increased by such agents through improvements in cardiac performance consequent upon reduced afterload, despite falls in arterial oxygen tension occasioned by worsening shunt. ${ }^{10}$

Given that the discovery of a pharmacologically distinct receptor population in the pulmonary circulation has proved elusive, investigators have attempted to manipulate PVR in patients with lung injury using agents with particular pharmacological or physical properties. For example, a rapidly metabolised drug with a very short half life administered intravenously may no longer possess biological activity by the time it reaches the systemic circulation. Thus, adenosine has been shown to have a vasodilator effect specific to the pulmonary circulation when infused into patients with primary pulmonary hypertension, ${ }^{11}$ but in biventricular failure it induces significant increases in pulmonary artery occlusion pressure, ${ }^{12}$ suggesting a negative effect on ventricular diastolic performance which would clearly be unhelpful in patients with cardiac function compromised by ALI/ARDS.

By contrast, the use of inhaled vasodilators is theoretically doubly attractive. Any lack of pharmacological specificity for the pulmonary circulation becomes less relevant, provided that agents are inactivated by the time the systemic circulation is reached. If the action of such drugs is confined to the area of deposition, then blood will be recruited to lung units to which the inspired gas has access, thereby reducing shunt fraction and PVR. To date, most laboratory and clinical experience has been gained in ALI/ ARDS using inhaled nitric oxide (NO)..$^{13-17}$ An increasing body of clinical evidence suggests that the theoretical advantages outlined above are borne out in practice, with beneficial reductions in PVR and improvements in gas exchange.

In 1993 Rossaint et al published the results of a small study of nine patients with ARDS. ${ }^{17}$ Nitric oxide, $18 \mathrm{ppm}$, was administered by inhalation for 40 minutes, producing a significant reduction in the mean pulmonary artery pressure, and an increase in the $\mathrm{PaO}_{2} / \mathrm{FiO}_{2}$ ratio. The mean shunt fraction was reduced significantly from $36 \%$ to $31 \%$. Seven patients were subsequently treated with inhaled NO for 3-53 days during which time the investigators were able to reduce the inspired oxygen concentration by $15 \%$. They did not observe any adverse systemic haemodynamic consequences. By contrast, infusion of intravenous prostacyclin caused an increase in shunt and a reduction in systemic arterial pressures.

Similar findings have been reported in similar patients using inhaled NO at considerably lower concentrations. ${ }^{16}$ Furthermore, NO at $2 \mathrm{ppm}$ completely reversed the increase in PVR associated with the hypercapnia resulting from low frequency ventilation, a technique commonly employed in the management of ARDS. Moreover, this modest dose of NO produced beneficial effects on gas exchange.

However, not all patients seem to benefit from NO inhalation and no firm data have emerged to suggest that it causes a significant reduction in ARDS-associated mortality. This may not be altogether surprising since such patients tend to die from the associated underlying disease or the twin complications of sepsis and multiple organ failure. Survival may therefore be an insensitive end point, and the achievement of physiological goals or reduced morbidity/ventilator time may represent more appropriate targets for controlled trials. ${ }^{18}$

Nevertheless, the encouranging preliminary results reported with administration of NO by inhalation to patients with ALI/ARDS have led to widespread uncontrolled use of this potentially exciting therapy. The logistics of its safe administration are complex. NO reacts with oxygen to form nitrogen dioxide which dissolves to form toxic nitrous acid. The reaction rate is dependent upon the available oxygen concentration, so the time it spends in combination with high concentrations of oxygen must be kept to a minimum. There are a number of ventilator circuits which have been designed specifically to overcome this problem, and simple nitrogen dioxide fuel cell analysers are available which should also contribute to patient monitoring and therefore safety.

However, the drug remains unlicensed and there is no standardised protocol of administration nor formalised means of monitoring systems of administration. Furthermore, the assumption that the evanescence of NO equates to a benign local action is almost certainly an oversimplification. NO reacts rapidly with haemoglobin ${ }^{19}$ and is therefore carried from the lung into the systemic 
circulation, albeit in modified form. Knowledge of the physiology of NO derivatives in animal models is increasing rapidly and providing contradictory results.

The most frequently quoted toxicology studies describe experiments in which non-diseased animals are exposed to inhaled NO. Exposure of rats to $1000 \mathrm{ppm}$ NO for 30 minutes, ${ }^{20}$ exposure of rabbits to $43 \mathrm{ppm}$ for six days, ${ }^{21}$ and long term studies (six months) in mice ${ }^{22}$ have not demonstrated histological, ultrastructural, or gravimetric evidence of pulmonary toxicity. Unfortunately, such investigations provide no guide to possible toxic effects in diseased lungs with ongoing inflammatory processes and cannot therefore be regarded as totally reassuring. Furthermore, rabbits inhaling $30 \mathrm{ppm}$ NO for 15 minutes displayed significantly prolonged bleeding times, and 300 ppm significantly reduced systemic arterial pressures. ${ }^{23}$

The availability of NO synthase (NOS) antagonists, such as $\mathrm{N}^{\mathrm{G}}$-monomethyl-L-arginine (L-NMMA), has enabled scientists to investigate the role of endogenous $\mathrm{NO}$ in a variety of physiological and pathological systems. In ALI/ ARDS, macrophages and activated neutrophils are recruited to the lung ${ }^{2425}$ where they release reactive oxygen species (ROS) ${ }^{2627}$ Hydrogen peroxide and nitrotyrosine, markers of ROS activity, have been detected in breath condensate $^{28}$ and lung tissue, ${ }^{29}$ respectively, from patients with ARDS. Furthermore, endotoxaemia stimulates the expression of the messenger RNA for the calcium-independent, inducible isoform of NOS (iNOS) in rats. ${ }^{30}$ In pathological states there may therefore be a secondary increase in NO generation. There is increasing evidence to suggest that NO may be an effective scavenger of $\operatorname{ROS}^{31}$ and may inhibit xanthine oxidase, ${ }^{32}$ an enzyme which produces superoxide. In this sense NO may be cytoprotective.

By contrast, under hypoxic conditions NO reacts with superoxide to form peroxynitrite ${ }^{33}$ which is profoundly cytotoxic. This reaction occurs three times faster than the scavenging of superoxide by the antioxidant superoxide dismutase. The exact nature of peroxynitrite toxicity is emerging slowly, but it may be responsible for surfactant damage and be directly injurious to proteins, ${ }^{34}$ producing nitrotyrosine residues. These have been detected in both animal models and in lung tissue from patients with ARDS.$^{29}$ In addition, peroxynitrite appears to inhibit metabolic processes in type II alveolar cells. ${ }^{35}$ The dysfunctional nature of surfactant in ARDS is well established and has been comprehensively reviewed elsewhere. ${ }^{36}$

The interrelationship of NO, superoxide, and peroxynitrite in the context of lipid peroxidation has been explored in vitro, ${ }^{37}$ the investigators concluding that $\mathrm{NO}$ can both stimulate superoxide/peroxide/hydroxyl-induced lipid oxidation and also mediate oxidant protective reactions at higher rates of 'NO production. The pro-oxidant versus antioxidant outcome is thus critically dependent on relative concentrations of individual reactive species. They suggest a mechanism by which, under certain conditions, NO could terminate propagating lipid peroxidation chain reactions through a reaction with lipid peroxyl intermediates.

The biology of NO is therefore complicated and its actions seem to depend upon prevailing conditions. In ARDS the lung is likely to be primed to produce both endogenous NO and superoxide. The inspired oxygen concentration will be high, which may in itself be toxic. Inhaled NO may scavenge toxic radical species and terminate propagating chain reactions, but may equally combine with superoxide to form the high toxic peroxynitrite. Chronic hypoxia may lead to a downregulation of second messenger activation in vascular smooth muscle, reducing the vasodilator effect of exogenous $\mathrm{NO} .{ }^{38}$ If the patient then receives $\mathrm{NO}$ by inhalation at $20 \mathrm{ppm}$, a concentration several orders of magnitude greater than the estimated concentration of endogenous NO in alveolar gas, peroxynitrite levels may increase and fuel oxidant-mediated inflammation.

Infants with severe congenital heart disease, ${ }^{39}$ persistent fetal circulation, ${ }^{40}$ and diaphragmatic hernia ${ }^{41}$ often suffer considerable morbidity and mortality due to severe pulmonary hypertension. For these patients the issues may be different: they may die because of cardiac impairment consequent upon elevated PVR and the chance to control the circulation with NO may considerably increase their changes of survival. An enlarging literature supports this indication for inhaled NO therapy where different riskbenefit equations may apply.

Nitric oxide improves gas exchange and reduces PVR in some patients with ARDS, an attractive option in a condition desperately short of effective therapeutic interventions. For some this may mean the difference between survival and non-survival, and rapid growth in the (largely) unmonitored use of inhaled NO is understandable. However, the potential for harmful side effects may emerge increasingly as our understanding of the biology of NO increases. In this sense the principle of primum non nocere should not be forgotten. The information to allow a reasoned risk-benefit analysis of $\mathrm{NO}$ therapy may be extremely hard to obtain, but hopefully will be forthcoming.

Unit of Critical Care,

National Heart and Lung

STEPHEN J BRETT

Institute,

London, UK

1 Bernard GR, Artigas A, Brigham KL, Carlet J, Falke K, Hudson L, et al. The American-European Consensus Conference on ARDS. Am $\mathcal{f}$ Respir Crit Care Med 1994;149:818-24.

2 Danzker DR, Brook CJ, Dehart P, Lynch JP, Weg JG. Ventilation perfusion distributions in the adult respiratory distress syndrome. Am Rev Respir Dis 1979;120:1039-52.

3 Zapol WM, Snider MT. Pulmonary hypertension in severe acute respiratory failure. $N$ Engl f Med 1977;296:476-80.

4 Calvin JE, Quin B. Right ventricular pressure overload during acute lung injury: cardiac mechanics and the pathophysiology of right systolic dysfunction. $\mathcal{F}$ Crit Care 1989;4:251-65.

5 Pinsky MR. The role of the right ventricle in determining the cardiac output in the critically ill. Intensive Care Med 1993;19:1-2.

6 Radermacher P, Huet Y, Pluskwa F, Heigault R, Teisseire B, Lamaire F. Comparison of ketanserin and sodium nitroprusside in patients with severe ARDS. Anesthesiology 1988;68:152-7.

7 Melot C, Naeije R, Mois P, Hallemans R, Lejeune P, Jasper N. Pulmonary vascular tone improves pulmonary gas exchange in the adult respiratory vascular tone improves pulmonary gas exchange in the ad
distress syndrome. Am Rev Respir Dis 1987;136:1232-6.

8 Silverman HJ, Slotman G, Bone RC, Maunder R, Hyers TM, Kerstein $M D$, et al. Effects of prostaglandin $E_{1}$ on oxygen delivery and consumption $\mathrm{MD}$, et al. Effects of prostaglandin $\mathrm{E}_{1}$ on oxygen delivery and consumption in patients with the adult respiratory distress syndrome. R
prostaglandin $E_{1}$ multicentre trial. Chest 1990;98:405-10.

9 Bone RC, Slotman G, Maunder R, Silverman H, Hyers TM, Kerstein MD, et al. Randomized double-blind, multicentre study of prostaglandin $\mathrm{E}_{1}$ in patients with the adult respiratory distress syndrome. Chest 1989;96: 114-9.

10 Bihari D, Smithies M, Gimson A, Tinker J. The effects of vasodilation with prostacyclin on oxygen delivery and uptake in critically ill patients. $N$ Engl f Med 1987;317:397-403.

11 Morgan JM, McKormack DG, Griffiths MJD, Morgan CJ, Barnes PJ, Evans TW. Adenosine as a vasodilator in primary pulmonary hypertension. Circulation 1991;84:1145-9.

12 Haywood GA, Sneddon JF, Bashir Y, Jennison SH, Gray HH, McKenna $\mathrm{J}$. Adenosine infusion for the reversal of pulmonary vasoconstriction in J. Adenosine infusion for the reversal of pulmonary vasoconstriction in 896-902.

13 Frostell CG, Blomquist H, Hedenstierna G, Lundberg J, Zapol WM. Inhaled nitric oxide selectively reverses human hypoxic pulmonary vasoconstriction without causing systemic vasodilation. Anesthesiology 1993;78:427-35.

14 Frostell C, Fratacci M-D, Wain JC, Jones R, Zapol WM. Inhaled nitric oxide: a selective pulmonary vasodilator reversing hypoxic pulmonary vasoconstriction. Circulation 1991;83:2038-47.

15 Gerlach H, Pappert D, Lewandowski K, Rossaint R, Falke KJ. Long term inhalation with evaluated low doses of nitric oxide for selective improvement of oxygenation in patients with adult respiratory distress syndrome. Intensive Care Med 1993;19:443-9.

16 Puybasset L, Rouby JJ, Mourgeon E, Stewart TE, Cluzel P, Arthaud M, al. Inhaled nitric oxide in acute respiratory failure; dose response curves. Intensive Care Med 1994;20:319-27.

17 Rossaint R, Falke KJ, Lopez F, Slama K, Pison U, Zapol WM. Inhaled nitric oxide for the adult respiratory distress syndrome. $N$ Engl $₹$ Med 1993;328:399-405.

18 Petros AJ, Marshall JC, van Saene HKF. Should morbidity replace mortality as an endpoint for clinical trials in intensive care? Lancet 1995;345:369-71. 
19 Oda H, Kusumoto S, Nakajimia T. Nitrosyl-hemoglobin formation in the blood of animals exposed to nitric oxide. Arch Environ Health 1975;30: 453-65.

20 Stavert DM, Lehnert BE. Nitrogen oxide and nitrogen dioxide as inducers of acute pulmonary injury when inhaled at relatively high concentrations for brief periods. Inhal Toxicol 1990;2:53-7.

21 Hugod C. Effect of exposure to $43 \mathrm{ppm}$ nitric oxide and $3.6 \mathrm{ppm}$ nitrogen dioxide on rabbit lung. Int Arch Occup Environ Health 1979;42:159-67.

22 Oda H, Nogami H, Kusomoto S, Nakajima T, Kurata A, Imai K. Long term exposure to nitric oxide in mice. $\mathcal{F f p n}$ Soc Air Pollut 1976;11:150-60.

23 Hogman M, Frostell C, Arnberg H, Sandhagen B, Hedenstierna G. Prolonged bleeding time during nitric oxide inhalastierna G. Prolonged bleeding time during nit

24 MacNee W, Selby C. Neutrophil traffic in the lungs: role of haemodynamics, cell adhesion, and deformability. Thorax 1993;48:79-88.

25 Streiter RM, Lukacs NW, Standiford TJ, Kunkel SL. Cytokines and lung inflammation: mechanisms of neutrophil recruitment to the lungs. Thorax 1993;48:765-9.

26 Till GO, Johnson KJ, Kunkel R, Ward PA. Intravascular activation of complement and acute lung injury: dependency on neutrophils and toxic oxygen metabolites. $\mathcal{F}$ Clin Invest 1981;69:1126-35.

27 Cochrane CG, Spragg R, Revak SD. Pathogenisis of the adult respiratory distress syndrome: evidence of oxidant activity in bronchoalveolar lavage fluid. $\mathcal{F}$ Clin Invest 1984;69:543-53.

28 Baldwin RB, Simon RH, Grum CM, Ketai LH, Boxer LA, Devall LJ. Oxidant activity in expired breath of patients with adult respiratory distress syndrome. Lancet 1986;i:11-14.

29 Haddad IY, Pataki G, Hu P, Galliani C, Beckman JS, Matalon S. Quantitation of nitrotyrosine levels in lung sections of patients and animals with acute lung injury. $\mathcal{F}$ Clin Invest 1994;94:2407-13.

30 Liu SF, Adcock IM, Old RW, Barnes PJ, Evans TW. Lipopolysaccharide treatment in vivo induces widespread tissue expression of inducible nitric oxide synthase mRNA. Biochem Biophys Res Commun 1993;196:1208-13.

31 Rubanyi GM, Ho EH, Cantor EH, Lumma WC, Parker Botelho LH.
Cytoprotective function of nitric oxide: inactivation of superoxide radicals produced by human leukocytes. Biochem Biophys Res Commun 1991;181: 1392-7.

32 Fukahori $M$, Ichimori $K$, Ishida $H$, Nakagawa $H$, Okino $H$. Nitric oxide reversably suppresses xanthine oxidase activity. Free Rad Res 1994;21: 203-12.

33 Beckman JS, Beckman TW, Chen J, Marshall PA, Freeman BA. Apparent hydroxyl radical production by peroxynitrite: implications for endothelia injury from nitric oxide and superoxide. Proc Natl Acad Sci USA 1990; 87:1620-4.

34 Haddad IY, Crow JP, Hu P, Ye Y, Beckman J, Metalon S. Concurrent generation of nitric oxide and superoxide damages surfactant protein $\mathrm{A}$ generation of nitric oxide and sup

$35 \mathrm{Hu}$ P, Ischiriopoulos H, Beckman JS, Matalon S. Peroxynitrite inhibition of oxygen consumption and sodium transport in alveolar type II cells. $\mathrm{Am}$ f Physiol 1994;266:L628-34.

36 Lewis JF, Jobe AH. Sufactant and the adult respiratory distress syndrome. Am Rev Respir Dis 1993;147:218-33.

37 Rubbo H, Radi R, Trujillo M, Telleri R, Kalyanaraman B, Barnes S, et al. Nitric oxide regulation of superoxide and peroxynitrite-dependent lipid peroxidation. F Biol Chem 1994;269:26066-75.

38 Crawley DE, Zhao L, Giembycz MA, Liu SF, Barnes PJ, Winter R, et al. Mechanism for the impairment of endothelial-dependent vasodilation in rats exposed chronically to hypoxia. Am ₹ Physiol 1992;263:L325-32.

39 Roberts JD, Lang P, Bigatello LM, Vlahakes GJ, Zapol WM. Inhaled nitric oxide in congenital heart disease. Circulation 1993;87:447-53.

40 Kinsella JP, Neish SR, Ivy DD, Shaffer E, Abman SH. Clinical responses to prolonged treatment of persistent pulmonary hypertension of the newborn with low doses of inhaled nitric oxide (see comments). $\mathcal{F}$ Paediat 1993;123:103-8.

41 Frostell CG, Lonnqvist PA, Sonesson SE, Gustafsson LE, Lohr G, Noack G. Near fatal pulmonary hypertension after surgical repair of congenital diaphragmatic hernia. Successful use of nitric oxide. Anaesthesia 1993;48: 679-83. 